\title{
Under the new normal vocational education fair path selection
}

\author{
Liu Yanming ${ }^{1, ~ a, ~ G a o ~ J i a n b o ~}{ }^{1, b}$ \\ ${ }^{1}$ Jiangxi Science \& Technology Normal University, Nanchang, Jiangxi, 330013, P.R. China \\ a 498225491@qq.com, ${ }^{\mathrm{b}}$ gaojianbo1971@163.com
}

Keywords: The new normal; Vocational education; Education justice; Path selection

\begin{abstract}
At present, our country's vocational education business got continuous development under the new normal, and it has been more and more people's attention. So, to vocational education fair path choice is very important. Vocational education fair is our country chose the path of education under the new normal main basis, only reasonable choice based on the vocational education fair path, to make our country's education is more fair and reasonable. Based on normal vocational education fairness path, the paper analyzed the choice of hope in the future vocational education can achieve better results.
\end{abstract}

\section{Introduction}

The stand or fall of vocational education and economic development in our country there is a close relationship. Economic development is an important basis for the development of vocational education, in turn, the stand or fall of vocational education and has a direct influence on the development of the economy. Only the economic development of strong enough to make the vocational education's scale is enough big, the quality is good enough, fast enough to development. The development of the vocational education can provide state in the process of economic development with a large number of technical and professional skills, make the economy of the rapid development of our country. Vocational education is the foundation of today's society fair, fair and effective expanding social fairness in education. Along with the development of the cause of education in our country, the education fair subject has been more and more people's attention, however, is different from ordinary education, vocational education fair, however, are not under the attention of people, therefore, under the new normal, we need to correctly choose the path of the vocational education, make vocational education more equitable.

\section{2. vocational education fair connotation}

At present, vocational education fair connotation mainly has the following several aspects. An analysis of from people were affected by the level of education. It think vocational education fair is mainly divided into three points: first, to make everyone has the right to receive vocational education; Second, schools and teachers can treat every student fairly; Third, each students receiving education can learn skills in accordance with its characteristics, to provide help for later obtain employment, which can effectively reflect the vocational education fairness. From the analysis of the level of social justice. It argues that vocational education fair is occupies the important position of social justice, and it can enjoy equal rights with ordinary education. Three from the level of the comprehensive analysis [1]. It argues that vocational education fair is not only a insider for fair, also can enjoy equal rights in the social fair. Four from whole process analysis. It think fairness in vocational education includes starting point fair, process justice and result justice. , the starting point of the so-called fairness refers to before the implementation of free secondary vocational education policy, the education teaching of secondary vocational charges should stay in a low level, the family is not rich students can still afford to school, so as to realize the admission of vocational education fair. Funds of education process fairness is refers to the state accordingly, the distribution of the secondary vocational schools and ordinary schools should enjoy the same benefits, achieve career fair in the process of teaching. Result fairness refers to have graduated from the secondary vocational student's can have a stable job, and 
can have a more stable source of funds, use to make up for the secondary vocational student's not receive higher education and bring the phenomenon of insufficient economic source, the result education is more fair.

\section{The existence of vocational education under the new norm of unfair phenomena}

At present, there is still part of vocational education unfair phenomena, such as uneven distribution of vocational education's internal resources, teachers are not enough, unfair education starting point and so on, these factors are very common in the vocational education in our country, however, to these questions is no corresponding solution and protective measures. There are some scholars will vocational education of our country present stage using the Angle of the researcher has carried on the corresponding analysis, which will exist in various stages of unfair clearly pointed out that [2]. At the beginning stage of the vocational education, the existence of unfair is primarily between urban and rural vocational education standards exist unfair phenomenon. Between rural and urban areas due to the student's growth environment, family background, and the quality of parents and so on, in addition, there are still some vocational school admissions standards unfair, unfair social concepts and so on, makes the students causes students starting point is not equal. In the process of vocational education, as well as the demonstration of the exemplary vocational colleges universities between the unfair phenomenon is also very obvious. Both in the faculty of the exemplary vocational colleges and teaching resource configuration, or in teaching field, there are unfair phenomena. In addition, in the professional teaching process, often appear teachers ignore the rural students, teaching quality and students participate in many opportunities unfairness phenomena; Vocational education unfair results mainly reflects on the students' employment and wages. These unfair phenomena make vocational education in the process of our development is limited by a lot. At present, the existence of vocational education in our country, the function, the object and the situation of the education funds and so on are marginalized, people for vocational education is not high, esteemed multi-cores vocational school students are vulnerable groups, the original life there are many unfair. So, the unfair for teaching is weak to resist, can only silently to accept.

\section{4. under the new normal vocational education fair path selection}

\subsection{To strengthen the government department's attention}

To implement vocational education under the new normal fair, you first need to the support from government departments, and fully exert the function of the government cannot come out. Government departments to clear their own in vocational education fair is the responsibility and obligation, and to exert the leading role of government departments, to accord with the teaching characteristics of vocational schools to develop a policy, and make it as soon as possible the realization of the vocational education fair [3]. Government departments for students in rural areas and disadvantaged students must carry on the focus of attention, so it can guarantee is the same as the starting point of the entrance position for professional studies. Government department for education funding and teaching equipment must carry on the reasonable configuration, increasing investment for vocational schools, allow them to keep on the same starting line with ordinary schools.

\subsection{To improve the society level vocational education were}

Some scholars in the study found that in the process of vocational education fair to make vocational education more fair, you first need to improve school for vocational education, esteemed and society need to know about vocational education existence value and meaning, to lay a good foundation for the vocational school students' employment. In the process of teaching in vocational schools, still need to introduce market mechanism, for example, fair competition, talent flow and university-enterprise cooperation mechanism, make professional college cultivate students to have good professional skills, in the enterprise or industry factory can also be a perfect adaptation.

\subsection{To improve the fairness of the vocational education itself}


In terms of the vocational education itself, should expand the scope of recruit students. For the choice of students should not only the students, can also recruit some of the laid-off workers and rural labor personnel, etc., make vocational education truly to be fair to everyone. As a result, not only can make the corresponding employment pressure relief of the society, but also gradually realize vocational education fairness. In vocational colleges, but also can implement the corresponding student exchange mechanism, so as to make the different schools, good communication between students of different levels of education, to promote learning quality gradually enhanced. In vocational school teaching materials in the process of writing, in addition to having a normal technical knowledge, you can also add some more training subjects, training students' practical ability and creative thinking.

\section{Vocational education under the new normal fair proposal}

In recent years, China's vocational education fair is more and more attention to, and carried on the thorough research to its, thus for the development of vocational education fair provides more theoretical support. Among vocational education fair research process, due to the connotation of vocational education fair and insufficient knowledge also has certain related elements, making the study of vocational education fair cannot undertake unity. So, in the process of research on vocational education fair, must first clear the connotation of vocational education, and its relevant factors must also be a clear understanding. Moreover, with the concept of fairness and equality cannot be confused. Vocational education fairness refers to everyone in the process of receive vocational education can be fair and reasonable evaluation; In vocational education refers to the equality in the process of students receive vocational teaching, can enjoy the same standard. Finally, the need to build a unique to vocational education fair research paradigm and discourse system, so it can fully reflect the characteristics of vocational education.

\section{6. conclusion}

To sum up, with the rapid development of society, the advance of economy, people for vocational education fair is more and more attention. In the process of study of vocational education, it is not difficult to found that there were unfair phenomenon, however, with the deepening of research, not fair to imagine that exist in the vocational education also obtained the corresponding solution. In vocational education fairness path selection process, need government departments, social activists and the joint efforts of the three aspects of vocational education itself, can make it get continuously development, make more people can accept to the fairness of vocational education, to promote the economic development of our country.

This article is one of the results of Jiangxi Education Science "Twelfth Five-Year Plan" 2015 annual key project " Vocational Education Equality Based on policy issues " (project number: 15ZD3L YB025), the corresponding author Liu Yanming.

\section{References}

[1]. Xia Lei, minister xie. Reflection and prospect of China's vocational education fair research, academic papers based on the quantitative statistical analysis [J]. Journal of vocational education BBS, 2014:9-13.

[2]. Huang Congying. The development of vocational education in our country under the new normal difficulty and path selection [J]. Journal of education research, 2015, 12, 51-56.

[3]. Xu Jinru Gu Xinmei. Education fair development of vocational education from the perspective of path selection [J]. Journal of education and profession, 2014:24-26. 